What Does the French Public Think About Inclusive Education?

Mickaël Jury

Université Clermont Auvergne, ACTé, F-63000 Clermont-Ferrand, France

Kamilla Khamzina

Université Clermont Auvergne, ACTé, F-63000 Clermont-Ferrand, France

Anne-Laure Perrin

Univ. Lille, ULR 4072 - PSITEC - Psychologie : Interactions Temps Émotions Cognition, F-59000 Lille, France

Natacha Serour

Université Clermont Auvergne, ACTé, F-63000 Clermont-Ferrand, France

Emmanuel Guichardaz

Trisomie 21 France, F-42000 Saint-Etienne, France

This paper has been accepted for publication in Journal of Intellectual \& Developmental Disability.

This version is a post-print.

Correspondence concerning this article should be addressed to Mickaël Jury, INSPE Clermont Auvergne, 36 avenue Jean Jaurès, 63400 Chamalières, France. mickael.jury@uca.fr. 


\begin{abstract}
Background: Students with intellectual disabilities are not yet fully included in mainstream education. Among the variables that could explain this situation, the present paper investigates public attitudes towards inclusive education and notably examine how these ones vary according to students' type of disability (i.e. an intellectual, a communicational, a sensory, a motor, or a specific learning one).

Method: Data were extracted from an online opinion poll on inclusive education policy conducted on a representative sample of the French population in terms of age, sex, socio-economic status and place of residence $(N=1,001)$.

Results: The present analyses indicated that the public are less favourable to the inclusion of students with an intellectual disability in comparison with students with autism spectrum disorder, a sensory disability, specific learning disabilities or a motor disability. Participants who are familiar with disability seem to express more favourable attitudes than those who are not.
\end{abstract}

Conclusions: The present study contributes to a better understanding of public attitudes towards inclusive education and opens perspectives to develop more inclusive societies.

\title{
Keywords
}

Public attitudes, disability, Down syndrome, autism, inclusive education 


\section{What Does the French Public Think About Inclusive Education?}

Countries all over the world are urged to endorse inclusive policies that consist in setting up appropriate and effective measures to facilitate the full participation of persons with disabilities within the society (United Nations, 2006). In the educational domain, schooling systems are thus encouraged to allow every student, regardless of their differences in ability, culture, gender and language to follow the curriculum within regular schools and to benefit from an inclusive education (UNESCO, 1994). However, despite these intentions, a large number of students with special educational needs, students who face learning difficulties or disabilities that make learning more difficult for them than for same-aged children without learning difficulties or disabilities, are still not fully included in mainstream systems. For example, within the French context, $21.5 \%$ of students with intellectual disabilities are excluded from the mainstream educational system (DEPP, 2019). This trend is not a French specificity since it could also be observed in other countries like, for example, the USA (National Center for Education Statistics, 2019).

To explain this state of affairs, reasons like the lack of funding, the lack of training or teachers' negative attitudes towards inclusive education are regularly mentioned (see for example Hind et al., 2019). However, the success of inclusive policies seems also to be linked to general public attitudes towards individuals with disabilities and their participation within society. Indeed, as detailed below, it can be assumed that the more positive the public attitudes are, the more likely individuals with disabilities will participate within their community (Morin et al., 2013; Scior, 2011). As a result, to improve the understanding of the persistent difficulties of implementing inclusive education policies, the present paper examines, within the French context, public attitudes towards inclusive education, particularly regarding students with intellectual disabilities in comparison with other types of disability.

\section{Attitudes towards Individuals with Intellectual Disabilities}

Due to many changes within our societies (e.g. deinstitutionalization, employment policy, media attention), attitudes towards inclusive policies and the social participation of individuals with intellectual disabilities tend to improve (Rees et al., 1991; Scior et al., 2010). If these changes appear to be very positive at a first sight, a closer look at the literature may reduce this optimism.

Indeed, it turns out that a minority of people still believe that individuals with intellectual disabilities should live in segregated settings (see Burge et al., 2007; Crowson et al., 2013) for their own protection (Cole, 1999). People also seem to be uncomfortable interacting with them, maintaining social distancing (Ouellette-Kuntz et al., 2010) and feeling negative emotions about them (e.g. pity, fear, see Findler et al., 2007). In addition, when attitudes are measured indirectly - in an implicit way it is found that they are less positive and even considerably more negative than expected (Wilson \& Scior, 2014). Finally, research in the social psychology field has found that these individuals face consistently negative stereotypes that could impair their social inclusion: if they are perceived as warm, they are also perceived as incompetent (Fiske et al., 2002; Krischler et al., 2018; Rohmer \& Louvet, 2011).

As a result, one may wonder what the public really thinks about the social participation of individuals with intellectual disabilities in our societies. Here, we seek to investigate this question 
regarding inclusive education, considered as one of the major transformations to be made in order to further develop inclusive societies (Thomas, 1997; UNDESA, 2009).

\section{Attitudes towards Inclusive Education}

Attitudes towards inclusive education refer to the extent to which individuals are favourable to a policy asking educational systems to ensure that students with disabilities can access an inclusive, quality and free primary education and secondary education on an equal footing with others (c.f. Article 24 of the Convention on the Rights of Persons with Disability, United Nations, 2006).

Results from multiple studies conducted with teachers, parents of students with special educational needs or students without special educational needs showed that these attitudes are often mixed (for reviews see de Boer et al., 2010, 2011, 2012). For example, if most teachers seem sincerely convinced of the value of including students with special educational needs in the mainstream system, they sometimes also associate disability with negative features and express negative attitudes accordingly. Moreover, these attitudes seem to vary depending on multiple factors like teaching efficacy (Desombre et al., 2019), training (Tournaki \& Samuels, 2016) or students' type of disability. Indeed, teachers are less likely to support inclusive education for students with intellectual disabilities or autism spectrum disorder in comparison with those with motor disability (Jury et al., 2020). Thus, if a lot is known about teachers' attitudes towards inclusive education, very little research has been done to investigate what public attitudes towards this policy are (Burge et al., 2008; Pace et al., 2010; Scior et al., 2020).

Public attitudes are, however, particularly important to consider since they are known for their potential impact on the actors of changes across many social issues (see Karali et al., 2014, for an example in environmental domain). Indeed, they could affect the quality of community integration and social participation of individuals with disabilities (Burge et al., 2008; Morin et al., 2013) and lead to discrimination and prejudice towards them (Morin et al., 2013; Peace et al., 2010). Consequently, depending on their valence, they might either represent leverage or a barrier to the successful implementation of inclusive education policies in mainstream educational systems.

Among the few research that has been conducted on this specific question, Pace and colleagues (2010) notably showed that out of a sample of 5,399 U.S. citizens, $25.3 \%$ agreed that students with Down syndrome should go to special schools. In the same vein, Scior and colleagues (2020, p. 4) indicated that: "despite broad agreement with the principle of inclusion, in many countries the general public reportedly continued to view inclusion as impractical and unachievable, and view specialist educational and residential settings as best placed to meet the needs of persons with [intellectual disabilities]". Nonetheless, this conclusion is made solely based on experts' views and may not reflect the public's real attitudes. As a result, the same authors called for more research "with representative general population samples" (p. 8).

Therefore, the present study seeks to examine public attitudes towards inclusive education within a French representative sample. This context is particularly interesting since France has the specificity of being a developed Western country, implying that the public should have more positive attitudes regarding inclusive policies (in comparison with Eastern countries, see Scior et al., 2010) and 
at the same time a rather young "inclusive" country. Indeed, the inclusive policy was set up in 2005 and became an explicit goal within the French educational system in 2013. Previously, France offered mostly segregated, then integrated, educational possibilities for students with special educational needs (for historical reviews, see Mazereau, 2012; Ventoso-Y-Font \& Fumey, 2019). Finally, little is known regarding the French public attitudes regarding intellectual disability - in Scior's review (2011), only one study reported attitudes from a French sample-.

\section{Overview and Hypothesis}

Based on the previous results, we seek to explore and describe French public attitudes towards inclusive education and notably those regarding students with an intellectual disability in comparison with other types of disability. Indeed, as evoked above, it has been shown that teachers' attitudes depend on the types of disability and notably that the more challenging for the teaching practices the disability is, the less favourable teachers' attitudes are (Jury et al., 2020; see also Avramidis et al., 2000). We argue that the same rationale could apply for the public attitudes.

As a result, public attitudes towards inclusive education were compared across five different types of disability: intellectual disability (i.e. Down syndrome), motor disability (i.e. students with a wheelchair), specific learning disabilities and difficulties (i.e. dyslexia, dysphasia, or attention disorders), sensory disabilities (i.e. deaf or blind students) and a communicational one (i.e., autism spectrum disorder, ASD). Based on the literature (Jury et al., 2020; Pace et al., 2010) and notably the fact that students with an intellectual disability or ASD suffer from a lower perception of competence than students with a motor or a sensory disability (Rohmer \& Louvet, 2011), we expect public attitudes regarding the inclusion of students with an intellectual disability or ASD being less positive than the ones regarding the inclusion of students with students with a motor or a sensory disability. It is worth noting that since specific learning disabilities are not always acknowledged as disabilities, attitudes regarding the inclusion of students with such disabilities should be more positive than the ones regarding the inclusion of students with an intellectual disability or an ASD but not more positive than those regarding the inclusion of students with students with a motor or a sensory disability.

\section{Method}

\section{Participants and procedure}

We extracted data from an opinion poll conducted online in summer 2019 by Harris Interactive for the association "Trisomie 21 France" on inclusive education policy. The sample included 1,001 participants (534 women and 467 men, $M_{\text {age }}=49.88, S D_{\text {age }}=15.67$ ) randomly contacted from the company database. This sample was representative of the French population in terms of age, sex, socio-economic status and place of residence.

\section{Material}

The whole study included multiple questions about participants' perceptions regarding the difficulty faced by individuals with disabilities in our society and some of the questions specifically focused on inclusive education. 
Public attitudes were assessed through a single question asking participants to indicate the extent to which they were favourable regarding inclusive education for students with a motor disability (phrased "students with a wheelchair or a limited mobility"), a sensory disability (phrased "students deaf or blind"), a communicational one (phrased "students with autism"), an intellectual disability (phrased "students with intellectual disabilities like Down syndrome") and specific learning disabilities (phrased "students with learning disabilities like dyslexia, dysphasia, or attention disorders") on a (recoded) scale ( $1=$ totally unfavourable to $4=$ totally favourable).

At the end of the survey, participants were invited to complete demographic information. In addition to their sex and age, participants were asked to indicate their level of education (i.e. What is your educational level?), their family situation (i.e. Are you living with a child or children at home?) and their familiarity with disability, regardless of the type of disability (i.e. Do you know someone with a disability?). Four hundred and ten participants were considered as familiar with disability since they have indicated that they know someone with a disability, and 591 were considered as unfamiliar with disability. A full description of the sample is presented in Table 1. All material and data regarding this project can be accessed here: https://osf.io/zg3ws/?view only=cf5bac86aa474a882ad8a4e976f46a629

\section{Table 1}

Description of the sample

\begin{tabular}{llr}
\hline Variable & Levels & $\mathrm{N}(\%$ of the sample) \\
\hline Sex & Female & $534(53.35 \%)$ \\
& Male & $467(46.65 \%)$ \\
Level of & Below the Baccalauréat & $241(24.10 \%)$ \\
education & Baccalauréat or less than a & $568(56.80 \%)$ \\
& university degree & $191(19.10 \%)$ \\
& A university degree & $374(37.36 \%)$ \\
Family & Live with children at home & $627(62.64 \%)$ \\
situation & Live without children at home & \\
Familiarity & Familiar (i.e. know someone & $410(40.96 \%)$ \\
with disability & with a disability) & $591(59.04 \%)$ \\
& Unfamiliar & \\
\hline
\end{tabular}

Note. The Baccalauréat is the French final high school exam. 


\section{Results}

\section{Main analysis}

As indicated previously, we sought to explore public attitudes towards inclusive education depending on students' type of disability. It should be noted that this analysis was conducted while controlling for the influence of participants' familiarity with disability. This last variable was coded +1 if they were familiar (i.e. know someone with a disability) and -1 if they were unfamiliar with disability. Indeed, based on the literature, it could be expected that the more people are familiar with disability, the more positive their attitudes towards inclusive education would be (for a review see Scior, 2011)

Consequently, a repeated measures ANOVA was conducted with students' type of disability as a 5-level within-subject factor (i.e. motor disability, sensory disability, intellectual disability, autism spectrum disorder, and specific learning disabilities) and participants' familiarity with disability as a covariate. The Mauchly's test indicated that the assumption of sphericity had been violated, $p<.001$, therefore degrees of freedom were corrected using Huynh-Feldt estimates of sphericity $(\varepsilon=.87)$.

The analysis showed that students' type of disability influenced participants' attitudes, $F$ (3.49, 3482.92) $=144.47, p<.001, \eta_{p}^{2}=.13$. As illustrated by Figure 1 and post-hoc analyses with Bonferroni correction, attitudes towards inclusive education for students with an intellectual disability $(M=2.89$, $S E=.03)$ were the most negative and significantly differed with those regarding students with autism spectrum disorder $(M=2.95, S E=.03, p=.046)$, students with a sensory disability $(M=3.09, S E=$ $.03, p<.001)$, students with specific learning disabilities $(M=3.16, S E=.03, p<.001)$, and students with a motor disability $(M=3.37, S E=.03, p<.001)$. All other comparisons were significant (all $p s<$ .009).

Finally, the analysis revealed that participants who are familiar with disability $(M=3.17, S E=$ 0.03 ) were also more favourable than those who are not $(M=3.02, S E=0.03), F(1,999)=11.86, p<$ $.001, \eta_{p}^{2}=.012$. 


\section{Figure 1}

Estimated marginal means for participants' attitudes towards inclusive education depending on students' type of disability.

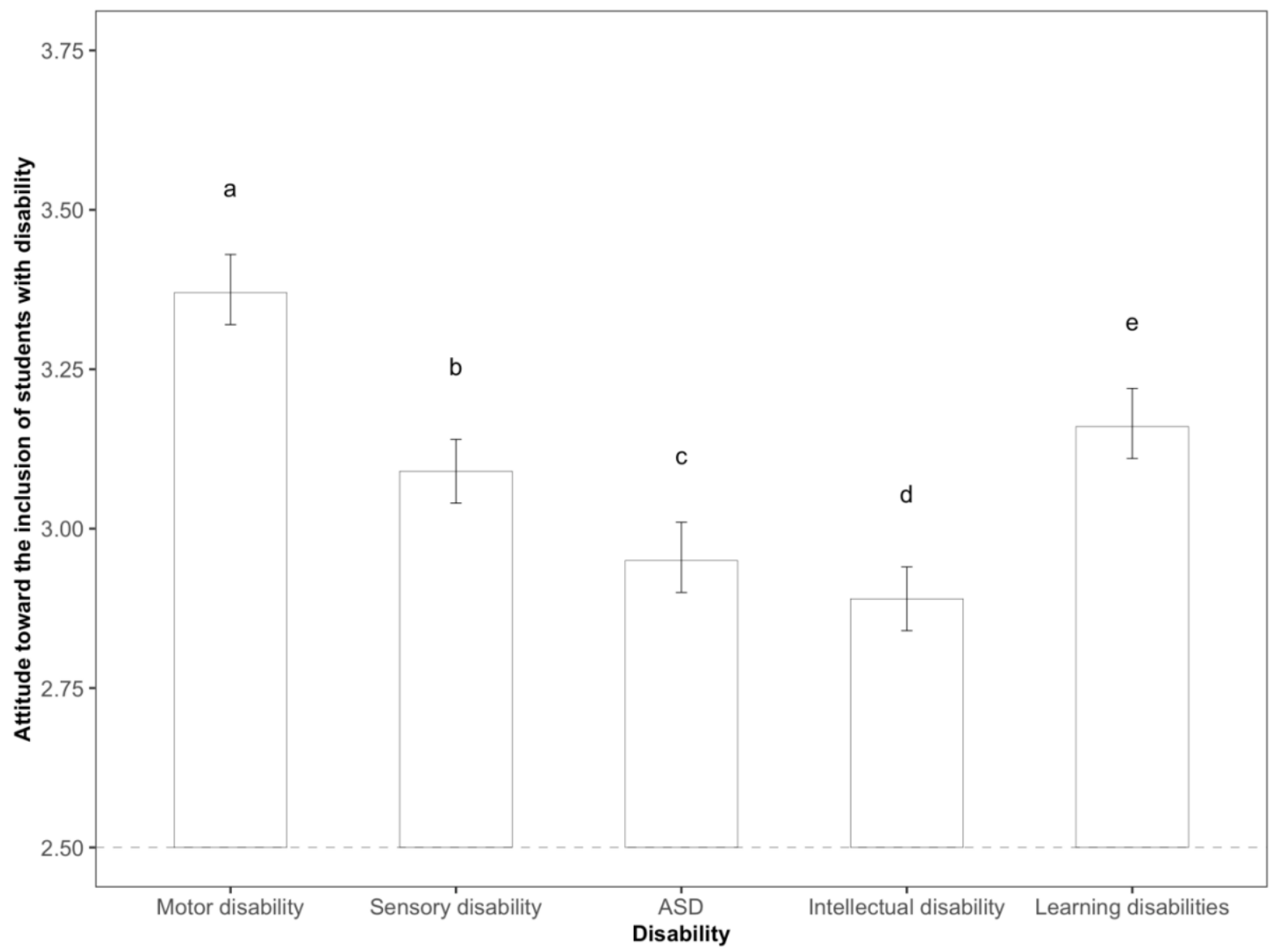

Note. ASD: Autism spectrum disorder. Different letters indicate significant differences between groups $(p<.05)$. Error bars represent $95 \% \mathrm{Cl}$.

\section{Additional exploratory analysis}

To complete these findings, an additional exploratory analysis was conducted on an item measuring the public preference for mainstream versus special education system depending on students' type of disability. More precisely, this item asked participants to indicate for these students if "It would be better for them to attend school in mainstream education." or if "It would be better for them to attend special schools", a dichotomous variable. Table 2 presents the frequencies of choices for each type of disability. If it should be acknowledged that this item does not refer specifically to one's viewpoints or dispositions towards the particular "object" of inclusive education (de Boer et al., 2011), that is, attitudes, we argue that it could be considered as a proxy of the previous measure and help us to better understand what the French public think about allowing students with disabilities to access to the mainstream system. 


\section{Table 2}

Frequencies of choices for mainstream education depending on students' type of disability.

\begin{tabular}{llccccc}
\hline & & \multicolumn{4}{c}{ Types of disability } \\
\cline { 3 - 6 } & & Motor & Sensory & ASD & Intellectual & Learning \\
\hline \multirow{3}{*}{ Choice } & $\begin{array}{l}\text { Mainstream } \\
\text { education }\end{array}$ & $85.91 \%$ & $57.24 \%$ & $54.95 \%$ & $51.35 \%$ & $73.63 \%$ \\
& $\begin{array}{l}\text { Special } \\
\text { education }\end{array}$ & $14.09 \%$ & $42.76 \%$ & $45.05 \%$ & $48.65 \%$ & $26.37 \%$ \\
\hline
\end{tabular}

Note. ASD: Autism spectrum disorder

Due to the dichotomous nature of the variable, a multilevel logistic regression was conducted to predict participants' preference for mainstream versus special education system for students depending on both, students' type of disability and participants' familiarity with disability. Following Sommet and Morselli's procedure (2017) and using the Ime4 package (Bates et al., 2015), results confirmed that in comparison with students with an intellectual disability, participants were 1.28 times more likely to support inclusive education for students with autism spectrum disorder in the mainstream system, $O R=1.28,95 \% \mathrm{Cl}[1.02,1.62], 1.51$ times more likely for students with a sensory disability, $O R=1.51,95 \% \mathrm{Cl}[1.20,1.90], 5.19$ times more likely for students with specific learning disabilities, $O R=5.19,95 \% \mathrm{Cl}[4.03,6.70]$, and 17.81 times more likely for students with a motor disability, $O R=17.81,95 \% \mathrm{Cl}[13.22,24.22]$. Since none of the $95 \%$ confidence intervals contain 1 , all these effects are statistically significant. However, the effect of the participants' familiarity with disability was not, $O R=1.12,95 \% \mathrm{Cl}[0.95,1.31]$. 


\section{Discussion}

The inclusion of students with intellectual disabilities in mainstream education is still rare in France (DEPP, 2019). Based on the literature arguing that public support is important for the successful implementation of an inclusive policy (Morin et al., 2013; Scior, 2011), the goal of the present paper was to explore public attitudes towards inclusive education within a French representative sample. More precisely, our goal was to investigate how students' type of disability could distinctly influence these attitudes.

Results from the main analysis indicated that the French public attitudes regarding inclusive education were the least positive for students with an intellectual disability in comparison with, in order of positivity, students with autism spectrum disorder, students with a sensory disability, students with specific learning disabilities and students with a motor disability. In the same vein, an additional exploratory analysis conducted on a preference score for mainstream versus special education system confirms that the former was less chosen for students with an intellectual disability in comparison with other students. Results regarding the familiarity with disability were more ambiguous since participants familiar with disability only expressed more positive attitudes than those who were unfamiliar in the first analysis but not a mainstream educational system preference, tending to confirm the uncertainty surrounding this variable (Scior, 2011).

Consequently, despite an apparent improvement over the years in attitudes towards individuals with intellectual disabilities (Scior et al., 2010), and the recent changes within the inclusion educational policy in the French context (Ventoso-Y-Font \& Fumey, 2019), the present results reinforce the idea that the latter are still facing reluctant attitudes regarding their social inclusion and that the public could consider that some students with disabilities are "worthier" than others when it comes to benefiting from a mainstream education, at least in France. As suggested above, such results might be explained by the negative stereotype regarding the competence of these students, the lowest expectations teachers may have regarding their academic achievement (see for example Cameron \& Cook, 2013), or by an ambiguous goal of protection of both, these students by considering that regular schools are not adapted to their needs and that they will suffer within this competitive context (Cole, 1999) and of their non-disabled peers (Pace et al., 2010). Indeed, the public might fear that including students with intellectual disabilities will be distracting and, as a consequence, impair other students' learning (Pace et al., 2010), a fear that seems often to be shared by teachers (see Brackenreed, 2008) even if not well supported by the literature (Ruijs, 2017; Sermier Dessemontet et al., 2013). In the same vein, the present findings revealed a weak difference, although significant, in terms of attitudes towards inclusive education for students with intellectual disabilities and those with autism spectrum disorder, both being the most negative ones in comparison with attitudes regarding other disabilities. Such a resemblance suggests that similar barriers, eventually resulting from existing negative stereotypes in terms of competence (Rohmer \& Louvet, 2011) but also behaviours (Dachez et al., 2016) can contribute to explain the exclusion that students with autism spectrum disorder could face within the mainstream educational system (Rattaz et al., 2020).

Nonetheless, in terms of perspective, we believe that the present results could help within the successful implementation of an inclusive education policy. More precisely, by showing that the public 
does not seem to embrace inclusive education for students with intellectual disabilities, it might contribute to explain why teachers also express negative attitudes towards those students (Jury et al., 2020). Therefore, in addition to transform teachers' workplaces in the pursuit of inclusive schooling, convincing the general population might also help teachers to change their attitudes and practices. Indeed, as mentioned above, research has shown that actors of change may modify their behaviours partly due to general population attitudes (Karali et al., 2014). As a result, even if this proposal is speculative, communicating to a larger public while promoting the inclusive education paradigm might represent an interesting way to foster attitudinal changes among teachers.

Finally, it should be noted that this study is not without limitations. First of all, the data are extracted from an opinion poll which did not use a validated scale to measure attitudes towards inclusive education (for example see Mahat, 2008) although the items used were straightforward. Second, previous results regarding this topic appear to be highly sensitive to the cultural context (Scior et al., 2010). However, since this study was conducted in a context in which the inclusive education paradigm is quite new, its results might not be very representative of any other context. Third, this study used an explicit attitude measure on a topic highly associated with social desirability (Lüke \& Grosche, 2018) that may have led the participants to express more positive attitudes than they actually have (Wilson \& Scior, 2014). As a support to this proposal, it can be noted that the estimated mean score regarding students with an intellectual disability and those with autism spectrum disorder, respectively 2.89 and 2.95 , could suggest rather favourable attitudes from the public regarding the inclusion of these students due to the closeness of these mean scores with the third point of the Likert scale, the "Favourable" one. Nonetheless, the question regarding their preferences rather revealed a mixed support regarding the participation of these students within the mainstream system $-51.35 \%$ and $54.95 \%$ respectively -. Altogether, these limitations imply that the results obtained here should be read cautiously and that a replication with a method limiting the social desirability bias, within another country, might represent an avenue to better understand the public attitudes.

To conclude, the present study contributes to a better understanding of public attitudes to inclusive policies and inclusive education in particular. While teachers' attitudes have been largely studied over the last decades, those of the wider population have received less attention. Investigating them is particularly important if we wish to have a clear insight into misconceptions about disability and develop more inclusive societies. 


\section{Authors' note}

This study was partially funded by the "Caisse Nationale de Solidarite pour l'Autonomie (CNSA) " (grant no. IReSP-17-AUT4-08).

Authors wish to thank the association Trisomie 21 France for letting us using their dataset.

All material and data regarding this project can be accessed here:

https://osf.io/zg3ws/?view only=cf5bac86aa474a82ad8a4e976f46a629

Authors have no conflict of interests.

All authors have contributed to, seen, and approved of the manuscript and agree to the order of authors as listed on the title page. 


\section{References}

Avramidis, E., Bayliss, P., \& Burden, R. (2000). A survey into mainstream teachers' attitudes towards the inclusion of children with special educational needs in the ordinary school in one local education authority. Educational psychology, 20(2), 191-211. https://doi.org/10.1080/713663717

Bates, D., Maechler, M., Bolker, B., \& Walker, S. (2015). Fitting linear mixed-effects models using Ime4. Journal of Statistical Software, 67(1), 1-48. https://doi.org/10.18637/iss.v067.i01

Brackenreed, D. (2008) Inclusive Education: Identifying Teachers' Perceived Stressors in Inclusive Classrooms. Exceptionality Education International, 18, 131-147. Retrieved from https://ir.lib.uwo.ca/eei/vol18/iss3/5

Burge, P., Ouellette-Kuntz, H., Hutchinson, N., \& Box, H. (2008). A quarter century of inclusive education for children with intellectual disabilities in Ontario: Public perceptions. Canadian Journal of Educational Administration and Policy, 87, 1-22. Retrieved from https://cjcrcc.ucalgary.ca/index.php/cjeap/article/view/42768

Burge, P., Ouellette-Kuntz, H., \& Lysaght, R. (2007). Public views on employment of people with intellectual disabilities. Journal of Vocational Rehabilitation, 26(1), 29-37. Retrieved from https://content.iospress.com/articles/journal-of-vocational-rehabilitation/jvr00360

Cameron, D. L., \& Cook, B. G. (2013). General education teachers' goals and expectations for their included students with mild and severe disabilities. Education and Training in Autism and Developmental Disabilities, 48(1), 18-30. Retrieved from https://www.jstor.org/stable/23879883?seq=1\#metadata info tab contents

Cole, P. G. (1999). The structure of arguments used to support or oppose inclusion policies for students with disabilities. Journal of Intellectual and Developmental Disability, 24(3), 215-225. https://doi.org/10.1080/13668259900034001

Crowson, H. M., Brandes, J. A., \& Hurst, R. J. (2013). Who opposes rights for persons with physical and intellectual disabilities? Journal of Applied Social Psychology, 43, E307-E318.

https://doi.org/10.1111/jasp.12046

Dachez, J., N'Dobo, A., \& Carrascal, O. N. (2016). Représentation sociale de l'autisme [Social representation of autism]. Les Cahiers Internationaux de Psychologie Sociale, 4, 477-500. https://doi.org/10.3917/cips.112.0477

De Boer, A., Pijl, S. J., \& Minnaert, A. (2010). Attitudes of parents towards inclusive education: A review of the literature. European Journal of Special Needs Education, 25(2), 165-181. https://doi.org/10.1080/08856251003658694

De Boer, A., Pijl, S. J., \& Minnaert, A. (2011). Regular primary schoolteachers' attitudes towards inclusive education: A review of the literature. International Journal of Inclusive Education, 15(3), 331-353. https://doi.org/10.1080/13603110903030089 
De Boer, A., Pijl, S. J., \& Minnaert, A. (2012). Students' attitudes towards peers with disabilities: A review of the literature. International Journal of Disability, Development and Education, 59(4), 379-392. https://doi.org/10.1080/1034912X.2012.723944

DEPP (2019). Repères et références statistiques. Ministère de l'éducation nationale et de la jeunesse.

Desombre, C., Lamotte, M., \& Jury, M. (2019). French teachers' general attitude toward inclusion: the indirect effect of teacher efficacy. Educational Psychology, 39(1), 38-50. https://doi.org/10.1080/01443410.2018.1472219

Findler, L., Vilchinsky, N., \& Werner, S. (2007). The multidimensional attitudes scale toward persons with disabilities (MAS) construction and validation. Rehabilitation Counseling Bulletin, 50(3), 166-176. https://doi.org/10.1177/00343552070500030401

Fiske, S. T., Cuddy, A. J., Glick, P., \& Xu, J. (2002). A model of (often mixed) stereotype content: competence and warmth respectively follow from perceived status and competition. Journal of personality and social psychology, 82(6), 878-902. https://doi.org/10.1037/0022-3514.82.6.878

Hind, K., Larkin, R., \& Dunn, A. K. (2019). Assessing teacher opinion on the inclusion of children with social, emotional and behavioural difficulties into mainstream school classes. International Journal of Disability, Development and Education, 66(4), 424-437. https://doi.org/10.1080/1034912X.2018.1460462

Jury, M., Perrin, A.-L., Rohmer, O., \& Desombre, C. (2020). Attitudes toward inclusion: An exploration of the interaction between teachers' status and students' type of disability. Manuscript submitted to European Journal of Special Educational Needs.

Karali, E., Brunner, B., Doherty, R., Hersperger, A., \& Rounsevell, M. (2014). Identifying the factors that influence farmer participation in environmental management practices in Switzerland. Human Ecology, 42(6), 951-963. https://doi.org/10.1007/s10745-014-9701-5

Krischler, M., Pit-ten Cate, I. M., \& Krolak-Schwerdt, S. (2018). Mixed stereotype content and attitudes toward students with special educational needs and their inclusion in regular schools in Luxembourg. Research in Developmental Disabilities, 75, 59-67. https://doi.org/10.1016/j.ridd.2018.02.007

Lüke, T., \& Grosche, M. (2018). What do I think about inclusive education? It depends on who is asking. Experimental evidence for a social desirability bias in attitudes toward inclusion. International Journal of Inclusive Education, 22(1), 38-53. https://doi.org/10.1080/13603116.2017.1348548

Mahat, M. (2008). The development of a psychometrically-sound instrument to measure teachers' multidimensional attitudes towardinclusive education. International Journal of Special Education, 23(1), 82-92. Retrieved from https://eric.ed.gov/?id=EJ814377

Mazereau, P. (2012). La République, l'école et les élèves en difficulté ou handicapés: une histoire française [The Republic, the school, the students with learning disabilities or difficulties : a French history]. Le francais aujourd'hui, 177(2), 29-37. https://doi.org/10.3917/lfa.177.0029 
Morin, D., Rivard, M., Crocker, A. G., Boursier, C. P., \& Caron, J. (2013). Public attitudes toward intellectual disability: A multidimensional perspective. Journal of Intellectual Disability Research, 57(3), 279-292. https://doi.org/10.1111/jir.12008

National Center for Education Statistics. (2019). Digest of Education Statistics, 2017 (2018-070). Retrieved from https://nces.ed.gov/fastfacts/display.asp?id=60

Ouellette-Kuntz, H., Burge, P., Brown, H. K., \& Arsenault, E. (2010). Public attitudes toward individuals with intellectual disabilities as measured by the concept of social distance. Journal of Applied Research in Intellectual Disabilities, 23(2), 132-142. https://doi.org/10.1111/i.1468$\underline{3148.2009 .00514 . x}$

Pace, J. E., Shin, M., \& Rasmussen, S. A. (2010). Understanding attitudes toward people with Down syndrome. American Journal of Medical Genetics Part A, 152(9), 2185-2192. https://doi.org/10.1002/ajmg.a.33595

Rattaz, C., Munir, K., Michelon, C., Picot, M. C., Baghdadli, A., \& ELENA study group. (2020). School Inclusion in Children and Adolescents with Autism Spectrum Disorders in France: Report from the ELENA French Cohort Study. Journal of Autism and Developmental Disorders, 50(2), 455466. https://doi.org/10.1007/s10803-019-04273-w

Rees, L. M., Spreen, O., \& Harnadek, M. (1991). Do attitudes toward persons with handicaps really shift over time? Comparison between 1975 and 1988. Mental Retardation, 29(2), 81. Retrieved from https://psycnet.apa.org/record/1991-24743-001

Rohmer, O., \& Louvet, E. (2011). Le stéréotype des personnes handicapées en fonction de la nature de la déficience. Une application des modèles de la bi-dimensionnalité du jugement social [Stereotype content of disability subgroups - Testing predictions of the fundamental dimensions of social judgement]. L'Année Psychologique, 111(1), 69-85.

https://doi.org/10.4074/s0003503311001035

Ruijs, N. (2017). The impact of special needs students on classmate performance. Economics of Education Review, 58, 15-31. https://doi.org/10.1016/j.econedurev.2017.03.002

Scior, K. (2011). Public awareness, attitudes and beliefs regarding intellectual disability: A systematic review. Research in developmental disabilities, 32(6), 2164-2182.

https://doi.org/10.1016/i.ridd.2011.07.005

Scior, K., Hamid, A., Hastings, R., Werner, S., Belton, C., Laniyan, A., ... \& Kett, M. (2020). Intellectual disability stigma and initiatives to challenge it and promote inclusion around the globe. Journal of Policy and Practice in Intellectual Disabilities. Advance online publication. https://doi.org/10.1111/jppi.12330

Scior, K., Kan, K. Y., McLoughlin, A., \& Sheridan, J. (2010). Public attitudes towardpeople with intellectual disabilities: A cross-cultural study. Intellectual and Developmental Disabilities, 48(4), 278-289. https://doi.org/10.1352/1934-9556-48.4.278 
Sermier Dessemontet, R., \& Bless, G. (2013). The impact of including children with intellectual disability in general education classrooms on the academic achievement of their low-, average-, and high-achieving peers. Journal of Intellectual and Developmental Disability, 38(1), 23-30. https://doi.org/10.3109/13668250.2012.757589

Sommet, N., \& Morselli, D. (2017). Keep Calm and Learn Multilevel Logistic Modeling: A Simplified Three-Step Procedure Using Stata, R, Mplus, and SPSS. International Review of Social Psychology, 30(1), 203-218. http://doi.org/10.5334/irsp.90

Thomas, G. (1997). Inclusive schools for an inclusive society. British Journal of Special Education, 24(3), 103-107. https://doi.org/10.1111/1467-8527.00024

Tournaki, N., \& Samuels, W. E. (2016). Do graduate teacher education programs change teachers' attitudes toward inclusion and efficacy beliefs? Action in Teacher Education, 38(4), 384-398. https://doi.org/10.1080/01626620.2016.1226200

UNESCO (1994). The Salamanca statement and framework for action on special needs education. Adopted by the world conference on special needs education: Access and equity. United Nations.

United Nations. (2006). Convention on the Rights of Persons with Disabilities and Optional Protocol. United Nations.

UNDESA (2009). Creating an Inclusive Society: Practical Strategies to Promote Social Integration. United Nations. Retrieved from https://www.un.org/esa/socdev/egms/docs/2009/Ghana/inclusive-society.pdf

Ventoso-y-Font, A., \& Fumey, J. (2019) Comprendre l'inclusion scolaire [Understanding the inclusive education paradigm]. CANOPÉ.

Wilson, M. C., \& Scior, K. (2014). Attitudes toward individuals with disabilities as measured by the Implicit Association Test: A literature review. Research in developmental disabilities, 35(2), 294321. https://doi.org/10.1016/j.ridd.2013.11.003 